\title{
Enhancement of Long-Term Potentiation by Cis-Unsaturated Fatty Acid: Relation to Protein Kinase $\mathbf{C}$ and Phospholipase $\mathbf{A}_{2}$
}

\author{
David J. Linden, Fwu-Shan Sheu, Kentaro Murakami, and Aryeh Routtenberg \\ Cresap Neuroscience Laboratory, Northwestern University, Evanston, Illinois 60201
}

\begin{abstract}
Previous correlative and interventive work from this laboratory has suggested that activation of protein kinase C (PKC) is important for the maintenance of the hippocampal longterm potentiation (LTP) response. One such study demonstrated that application of the cis-unsaturated fatty acid, oleate, a newly discovered PKC activator, could prolong the time course of LTP. The present study explored the mechanism of cis-unsaturated fatty acid action on LTP produced by perforant path stimulation. First, neither oleate application nor high-frequency stimulation alone produced a persistent change in synaptic transmission, while the 2 in conjunction did so. This suggests that oleate acts synergistically with the consequences of this stimulation to produce an enhancement of the LTP response. Second, oleate enhancement of LTP was more potent when applied in the perforant path synaptic terminal zone than in the dentate hilus, implying that the site of oleate action is at the synapse (where PKC is reported to be enriched). Third, translocation of PKC activity to the membrane was significantly increased after oleate-enhanced LTP relative to vehicle controls. PKC translocation was found to be unaltered by oleate application alone. Fourth, mepacrine blockade of the $\mathrm{Ca}^{2+}$-dependent enzyme phospholipase $A_{2}$, which releases endogenous oleate from membrane phospholipids, inhibited the timecourse of a persistent LTP response. This inhibition was shown to be reversible with oleate application. We propose that high-frequency stimulation produces an elevation of intracellular $\mathrm{Ca}^{2+}$, which then triggers phospholipase $\mathrm{A}_{\mathbf{2}}-\mathrm{me}$ diated oleate release. This free oleate then could act in synergy with processes that render PKC oleate-sensitive to produce a persistent activation of PKC, which is critical for and leads to the persistence of the LTP response.
\end{abstract}

In recent years, an expanding body of evidence has implicated protein phosphorylation as an important regulatory mechanism in the expression of neuronal plasticity (Gispen and Routtenberg, 1986). A model system of neuronal plasticity in the adult brain, in which persistent alterations of synaptic efficacy may be measured electrophysiologically, is hippocampal long-term potentiation (LTP; Bliss and Lomo, 1973). In this paradigm, the response of a population of dentate gyrus granule cells to a

\footnotetext{
Received March 9, 1987; accepted May 12, 1987.

This work was supported by Grants MH25281-12 and AFOSR 87-1046 to A.R We thank Cathie Haskell and Miriam Whitely for skillful technical assistance, Hope Robinson for data analysis, and David Lovinger, Shew Chan, Bob Nelson, Patti Colley, Ka Wong, and Maarten de Jonge for helpful discussions.

Correspondence should be addressed to Dr. Aryeh Routtenberg at the above address.

Copyright (c) 1987 Society for Neuroscience $0270-6474 / 87 / 113783-10 \$ 02.00 / 0$
}

constant afferent volley can be increased for hours or days following high-frequency stimulation of the afferent fibers. Work from this laboratory has suggested that activation of the $\mathrm{Ca}^{2+1}$ phospholipid-stimulated protein kinase C (PKC; Takai et al., 1977,1979 ), and consequent phosphorylation of one of its substrates, protein F1 (Akers and Routtenberg, 1985; Nelson and Routtenberg, 1985; Chan et al., 1986b), may mediate the persistence, but not the initiation of the LTP response (see Akers et al., 1986; Lovinger et al., 1986; Routtenberg, 1986; Routtenberg et al., 1986, for a review).

Activation of PKC by the well-characterized, phospholipase $\mathrm{C}$ (PLC)-mediated diacylglycerol signal is known to absolutely require $\mathrm{Ca}^{2+}$ and phospholipid (see Nishizuka, 1986, for a review). Work in our laboratory has shown that cis-unsaturated fatty acids, such as oleate, can stimulate purified PKC directly in the absence of $\mathrm{Ca}^{2+}$ and phospholipid (Murakami and Routtenberg, 1985; Murakami et al., 1986). Thus, Murakami and Routtenberg (1985) have suggested that a second transmembrane-signaling mechanism for PKC activation may involve cis-unsaturated fatty acid release from the 2 -acyl position of phospholipids by the action of the $\mathrm{Ca}^{2+}$-dependent enzyme, phospholipase $\mathrm{A}_{2}$ (PLA $)$.

We have observed that application of the cis-unsaturated fatty acid oleate in the dentate hilus prior to 2 brief trains of highfrequency stimulation caused the potentiated response to persist and grow, whereas application of either the trans-unsaturated fatty acid elaidate or the carrier solution caused the response to decay to baseline levels within 120 min (Linden et al., 1986a). We have proposed that cis-unsaturated fatty acids induce a persistent response through activation of PKC. It was also proposed that such compounds are released by LTP procedures: a transient rise in intracellular $\mathrm{Ca}^{2+}$ following high-frequency stimulation (Krnjevic et al., 1986) may stimulate PLA $\mathrm{A}_{2}$, thereby resulting in oleate liberation and consequent PKC stimulation.

In the present study, we explored the mechanism of cis-unsaturated fatty acid action on LTP by asking the following questions: Can oleate directly elicit LTP, or can it only act in concert with a process initiated by high-frequency stimulation? Does oleate enhance the LTP response through action at the synapse? Are there measurable changes in PKC activity present in cytosolic and membrane fractions (Kraft and Anderson, 1983) of oleate- and control-treated LTP animals? Will inhibition or PLA hasten the decay of an otherwise persistent LTP response, and, if so, will this inhibition be oleate-reversible?

A portion of the present results has appeared recently in abstract form (Linden et al., 1986b).

\section{Materials and Methods}

Recording. Adult, male Sprague-Dawley rats, weighing 150-200 gm, were obtained from Harlan Breeders. Animals were anesthetized with 
urethane, and a twisted-wire bipolar stimulating electrode was placed in the perforant path, the excitatory tract that projects from the entorhinal cortex to the dentate gyrus granule cells; specifically, the stimulating electrode was placed in the "bottleneck" of the perforant path (Lomo, 1971) to activate entorhinal-dentate synapses maximally (coordinates: 8.0 posterior, 4.5 lateral to bregma). A multibarreled micropipette for field potential recording and drug application was placed in either the hilus or the molecular layer of the dentate gyrus (coordinates: 4.0 posterior, 2.4 lateral to bregma), as guided by the perforant pathevoked response. The local potential recorded in the molecular layer is seen as a positive-going population spike superimposed on a negativegoing population EPSP. Both components of this response reverse as the recording electrode is advanced ventrally into the granule cell layer and dentate hilus (Andersen et al., 1966). Recordings in the molecular layer were made at the point of maximal EPSP slope response, approximately $200 \mu \mathrm{m}$ dorsal to the null zone. Likewise, hilar recordings were made at the point of maximal response in that zone, which was approximately $300 \mu \mathrm{m}$ ventral to the null zone.

Drugs. The unsaturated fatty acids applied were oleate (cis-9-octadecenoate, $\mathrm{Na}^{+}$-free; Aldrich) and elaidate (trans-9-octadecenoate, $\mathrm{Na}^{+}$free; Sigma). These compounds were directly dispersed into $20 \mathrm{~mm}$ Tris buffer, vigorously vortexed for $30 \mathrm{sec}$, nitrogen-bubbled and sonicated for $10 \mathrm{~min}$ (Murakami and Routtenberg, 1985) to yield a concentration

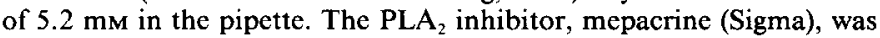
dissolved in $20 \mathrm{~mm}$ Tris to yield a concentration in the pipette of 67.6 mM.

Drug application. Separate barrels for recording (filled with normal saline), fatty acid application, and mepacrine application were used. Fatty acids were applied by iontophoresis. A $10 \mathrm{nA}$ anodal backing current was used to prevent leakage. The following time/cathodal current parameters were used to achieve different oleate doses: $38 \mathrm{pmol}-$ $25 \mathrm{nA}, 1 \mathrm{~min} ; 76 \mathrm{pmol}-25 \mathrm{nA}, 2 \mathrm{~min} ; 193 \mathrm{pmol}-25 \mathrm{nA}, 5 \mathrm{~min} ; 587$ pmol-25 nA, $15 \mathrm{~min} ; 1435 \mathrm{pmol}-38 \mathrm{nA}, 15 \mathrm{~min} ; 2569 \mathrm{pmol}-50$ $\mathrm{nA}, 15 \mathrm{~min}$. Ejections of ${ }^{14} \mathrm{C}$-oleate were used to quantify fatty acid release. Release of elaidate was not directly quantified. Previous studies (Linden et al., 1986a, and unpublished observations) have shown that release of the unsaturated fatty acids oleate and arachidonate is not significantly different across a wide range of time/current parameters.

It is difficult to determine the precise local concentration of a drug applied in vivo. However, making the order-of-magnitude assumption that the ejectate (in nanoliter volumes) is contained within $5 \mu$ l of hippocampal tissue, the following rough estimates of in vivo concentration may be derived: $38 \mathrm{pmol}=7.6 \mu \mathrm{M} ; 76 \mathrm{pmol}=15.2 \mu \mathrm{M} ; 193 \mathrm{pmol}=$ $38.6 \mu \mathrm{M} ; 587 \mathrm{pmol}=117.4 \mu \mathrm{M} ; 1435 \mathrm{pmol}=287.0 \mu \mathrm{M}$; and 2569 $\mathrm{pmol}=513.8 \mu \mathrm{M}$

Mepacrine was applied through a micropressure ejection system (design courtesy of Dr. J. Feldman; described in McCrimmon et al., 1986). Pulses of $20 \mathrm{msec}$ duration, $5 \mathrm{psi}$ pressure were delivered to the mepacrine-containing harrel with an interpulse interval of $5 \mathrm{sec}$, and the ejection volume was quantified by direct microscopic observation of the fluid miniscus within the barrel. Observation of the miniscus was repeated throughout the course of the experiment to ensure that no leakage occurred. The volume of the ejectate was $7.4 \mathrm{nl}$, and the amount was $500 \mathrm{pmol}$. Estimating the concentration in vivo by the method described above yields a value of $100 \mu \mathrm{m}$. This target concentration was chosen because a previous study had shown that $100 \mu \mathrm{M}$ mepacrine was the lowest concentration that would produce maximal PLA $\mathrm{P}_{2}$ inhibition $(\sim 80 \%)$, as measured by arachidonate release (Mallorga et al., 1980). In contrast, it has been demonstrated in our lab that $100 \mu \mathrm{M}$ mepacrine will cause a minimal $10-15 \%$ inhibition of purified PKC activation induced by oleate in the presence or absence of $\mathrm{Ca}^{2+}(\mathrm{K}$. Murakami, unpublished observations).

Data acquisition and analysis. Test pulses were delivered at $0.1 \mathrm{~Hz}$ with a $0.1 \mathrm{msec}$ pulse width. To allow for a physiologically relevant comparison across subjects, threshold was defined for each subject as the lowest-integer-stimulation voltage at which a population spike was evoked prior to high-frequency stimulation or drug application. For hilar recording, in which spike amplitude was the relevant measure, the test voltage was threshold plus $2 \mathrm{~V}$. This stimulation typically yields a response in which the spike amplitude is one-third of the EPSP amplitude, a condition previously shown to be optimal for demonstrating LTP (Routtenberg et al., 1985). For molecular layer recording, in which EPSP slope was the relevant measure, the test voltage was threshold minus $2 \mathrm{~V}$. This stimulation yields a population EPSP that will remain uncontaminated by population spike effects after high-frequency stimulation.

Groups of 5 consecutive waveforms were analyzed on-line to produce the final waveforms used for analysis. Population spike amplitude and population EPSP slope were measured as previously described (Routtenberg et al., 1985). These measures were normalized across subjects by conversion to percentage of baseline values. The baseline value was the first data point recorded after a $45 \mathrm{~min}$ period in which the response was allowed to stabilize following electrode placement.

High-frequency stimulation to inducc LTP was delivercd using 8 pulsc trains at $400 \mathrm{~Hz}, 0.4 \mathrm{msec}$ pulse width, and voltage at threshold plus 4 V. In this report, "high-frequency stimulation" refers to the above parameters, while "low-frequency stimulation" refers to $0.1 \mathrm{~Hz}, 0.1 \mathrm{msec}$ pulse width. Either 2 or $\mathbf{8}$ of these high-frequency trains were delivered, with a $30 \mathrm{sec}$ intertrain interval, to induce LTP. Eight trains have been demonstrated to produce LTP lasting for at least $120 \mathrm{~min}$, whereas 2 trains have been shown to produce a response that persists for $30 \mathrm{~min}$ and then decays to baseline within $120 \mathrm{~min}$ (Linden et al., 1986a; Routtenberg et al., 1986). The duration of the potentiation induced by 2 trains is significantly longer than that of posttetanic potentiation (McNaughton, 1982) and consequently is likely to represent a different phenomenon. Test pulses were delivered for $120 \mathrm{~min}$ following highfrequency stimulation, after which the brain was quickly frozen in situ by immersion of the animal in liquid nitrogen to prepare for subscquent biochemical analysis. Each experimental group contained 4 animals.

$P K C$ distribution assay. The region of the dorsal hippocampus where the fatty acids were applied was dissected in the cold room $\left(4^{\circ} \mathrm{C}\right)$ and homogenized with $40 \mathrm{vol}$ of buffer [ $50 \mathrm{~mm}$ Tris, $0.1 \mathrm{~mm}$ EDTA, $2 \mathrm{~mm}$ dithiothreitol (DTT), $10 \mu \mathrm{g} / \mathrm{ml}$ leupeptin, $\mathrm{pH} 7.5$, at $\left.4^{\circ} \mathrm{C}\right]$ in a custommade plastic homogenizer ( 20 up-and-down strokes). Homogenate (300 $\mu$ l) was centrifuged at $100,000 \times g$ for $1 \mathrm{hr}$ at $4^{\circ} \mathrm{C}$ and the supernatant was saved as the PKC cytosol fraction. PKC associated with the pellet was solubilized in buffer $(50 \mathrm{~mm}$ Tris, $1 \mathrm{~mm}$ EDTA, $1 \mathrm{~mm}$ EGTA, 2 mM DTT, $1 \%$ Triton X-100,10 $\mathrm{g} / \mathrm{ml}$ leupeptin) for $1 \mathrm{hr}$ at $4^{\circ} \mathrm{C}$, followed by a $100,000 \times g$ spin for $1 \mathrm{hr}$. The resultant supernatant was collected as the PKC membrane fraction. Both cytosolic and membrane fractions were applied to DEAE-cellulose minicolumns to eliminate the effect of inhibitors or phospholipid contamination. This minicolumn was preequilibrated with $2 \mathrm{ml}$ of column buffer ( $50 \mathrm{~mm}$ Tris, $1 \mathrm{~mm}$ EDTA, 1 mM EGTA, 2 mM DTT, pH 7.5, at $4^{\circ} \mathrm{C}$ ), washed twice with $1 \mathrm{ml}$ of buffer containing $50 \mathrm{~mm}$ Tris, $1 \mathrm{~mm}$ EGTA, and $2 \mathrm{~mm}$ DTT (pH 7.5 at $4^{\circ} \mathrm{C}$ ), and the PKC was eluted with $500 \mu \mathrm{l}$ of buffer containing 0.25 $\mathrm{M} \mathrm{KCl}, 50 \mathrm{~mm}$ Tris, $1 \mathrm{~mm}$ EGTA, and $2 \mathrm{~mm}$ DTT (pH 7.5 at $4^{\circ} \mathrm{C}$ ). PKC activity was measured as previously described (Murakami and Routtenberg, 1985).

\section{Results}

\section{Synergism between oleate application and high-frequency stimulation}

If oleate application acts synergistically with the consequences of 2 high-frequency trains to produce a persistent LTP response, then it could be predicted that neither oleate nor 2-train stimulation would produce a persistent facilitation of synaptic transmission when applied alone.

To test this prediction, the following within-animal design was used. Each of 4 groups had a recording/drug application clcctrode placed in the dentate hilus. Two groups received a single drug ejection (oleate or Tris) at $t=0$ (120 min prior to high-frequency stimulation). The other 2 groups received 2 drug ejections, first at $t=0$ and then just prior to high-frequency stimulation at $t=120$. All 4 groups had 2 high-frequency trains delivered at $t=135$. The dose of oleate delivered in each ejection was 1435 pmol, which has previously been shown to prolong the potentiated response produced by 2 high-frequency trains for $120 \mathrm{~min}$ (Linden et al., 1986a). This double-injection design allowed us to evaluate oleate effects in the same animal both in the absence of and in conjunction with 2 trains of high-frequency stimulation. 


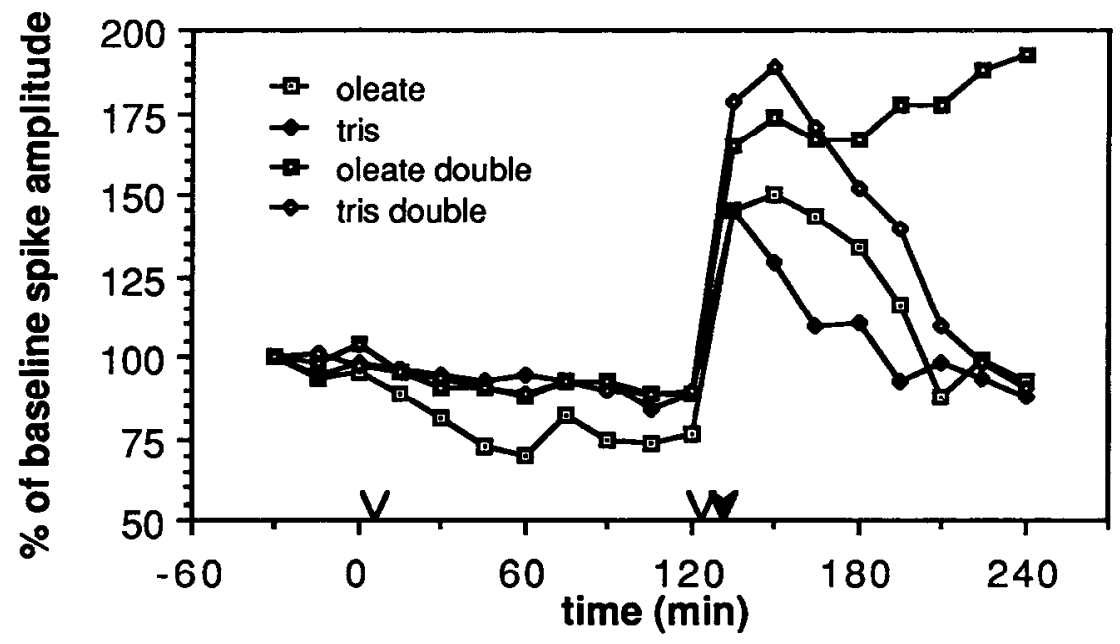

Figure 1. Synergistic action of oleate and high-frequency stimulation is time-dependent. Only oleate ejected at $t=120$ as well as $t=0$ (open arrowheads; oleate double) caused the potentiated response induced by 2 high-frequency trains (filled arrowhead) to persist and grow. Single ejections of oleate or Tris at $t=0$ or double ejections of Tris at $t=0$ and $t=120$ failed to enhance the potentiated response. Two-way ANOVAs run among pairs of groups yielded significant differences between oleate double and oleate $(F=10.42, d f=1,48, p<0.005)$, oleate double and Tris double $(F=9.68, d f=1,48, p<0.005)$, and oleate double and Tris $(F=9.73, d f=1,48, p<0.005)$. No significant difference was seen between Tris and Tris double $(F-2.11, d f-1,48, p>0.10)$. SEMs at $t-240$ that were representative of other time points were oleate, 11.3; Tris, 6.3; oleate double, 9.0; and Tris double, 3.7.

Ejection of $1435 \mathrm{pmol}$ of oleate into the dentate hilus in the absence of high-frequency stimulation did not affect the baseline population spike amplitude response (Fig. $1, t=0-120 \mathrm{~min}$ ). A 2-way analysis of variance (ANOVA), including all 4 groups across the time segment $t=0-120$, indicated no significant effect of drug treatment on the baseline response $(F=1.46, d f=3,108$, $p>0.20)$. The potentiated response $(t=135-240)$ was seen to persist and grow with application of oleate at $t=0$ and $t=120$ (immediately before the high-frequency stimulation); the response following all 3 other treatments, including the single oleate ejection at $t=0$, decayed to baseline at $t=240$. A 2-way ANOVA, including all 4 groups, from $t=135$ to $t=240$, indicated a significant effect of drug treatment on the potentiated response $(F=8.09, d f=3,96, p<0.001)$. In addition, the initial magnitude of potentiation measured at $t=135$ was not significantly affected by any of the drug treatments $(F=2.67, d f=$ $3,12, p>0.05$ ).

In sum, oleate ejection in conjunction with high-frequency stimulation produced a persistent potentiated response while leaving the initial magnitude of potentiation unaltered; oleate ejection alone in the hilus was ineffective in altering baseline synaptic transmission, and oleate ejection 120 min prior to highfrequency stimulation was ineffective in producing a persistent potentiated response. Thus, it would appear that a persistent potentiated response requires oleate application together with 2 high-frequency trains, that the persistent response so induced is not an additive, but rather a synergistic, effect of separate oleate and 2-train responses, and that the influence of oleate on LTP persistence cannot be ascribed to an effect on the initiating component of LTP.

\section{Dose-response function in the dentate hilus}

To determine whether the lack of response to oleate alone was a dose-related effect, 4 groups of animals received different doses of oleate applied in the dentate hilus, using the same double- injection protocol described above and illustrated in Figure 1 (Fig. 2).

Oleate alone, at all 4 doses tested, had no effect on the spike amplitude measure in the period $t=0-120(F=0.72, d f=$ $3,108, p>0.25$ ). However, following the second ejection of oleate, the highest dose, $2569 \mathrm{pmol}$, was seen to significantly impair the initial magnitude of potentiation at $t=135(F=$ $5.50, d f=3,12, p<0.025$ ). One-way ANOVA tests run among pairs of groups at this time point yielded significant differences between 193 and $2569 \mathrm{pmol}(F=34.89, d f=1,6, p<0.005)$ and between 587 and 2569 pmol $(F=15.89, d f=1,6, p<$ $0.01)$. No differences among the other 3 dose groups were found (all $p>0.25$ ).

A U-shaped dose-response curve was observed on the time coursc of the potentiated response; both the lowest (193 pmol) and the highest $(2569 \mathrm{pmol})$ doses failed to induce a persistent response. The $1435 \mathrm{pmol}$ dose alone caused the response to persist, and the $587 \mathrm{pmol}$ dose appeared to slow the response decay process. These observations are supported by a significant effect of dose across $t=135-240(F=9.15, d f=3,96, p<$ 0.001 ).

\section{Dose-response function in the dentate molecular layer}

If the prolongation of the LTP response produced by oleate application in the hilus is a result of action at perforant path synapses, then the dose required to prolong the LTP response should be lower for oleate application in this synaptic terminal zone. To test this hypothesis, each of 6 groups received different doses of oleate applied in the molecular layer at the region of maximal negativity, as measured by EPSP slope. The protocol for timing of ejections and high-frcquency stimulation was identical to that used in determining the hilar dose-response function. No effect of dose on the baseline population EPSP slope was seen following the first ejection $(F=0.62, d f=5,162, p>$ 0.25 ). The initial magnitude of potentiation was seen to be 


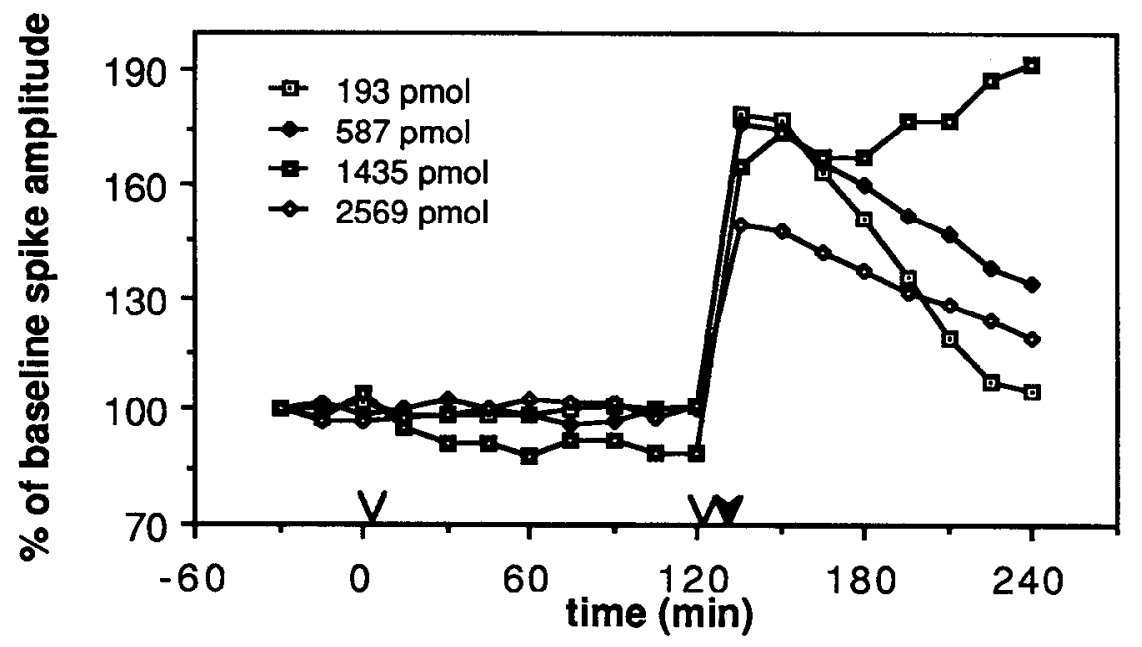

Figure 2. Oleate dose-response in the dentate hilus. A single dose of oleate, $1435 \mathrm{pmol}$, applied at $t=0$ and $t=120$ (open arrowheads) caused the potentiated response induced by 2 high-frequency trains (filled arrowhead) to persist and grow. The 193 and 2569 pmol responses decayed almost to baseline at $t=240$, whereas the $587 \mathrm{pmol}$ dose appeared to slightly retard the decay of the potentiated response. Two-way ANOVAs run among pairs of groups yielded significant differences between 1435 and $193 \mathrm{pmol}(F=10.04, d f=1,48, p<0.005), 1435$ and $587 \mathrm{pmol}(F=$ $6.92, d f=1,48, p<0.025), 1435$ and $2569 \mathrm{pmol}(F=22.66, d f=1,48, p<0.001)$, and 193 and $586 \mathrm{pmol}(F=9.35, d f=1,48, p<0.005)$. SEMs at $t=240$ were 193 pmol, 2.1; 587 pmol, 4.3; 1435 pmol, 9.0; and 2569 pmol, 2.1 .

drastically reduced at the 2 highest doses; at 1435 pmol, potentiation was completely inhibited, and at $587 \mathrm{pmol}$ it was reduced to approximately $40 \%$ of the Tris control value (Fig. 3 ).

The $193 \mathrm{pmol}$ dose was the most effective in prolonging the potentiated response; application of $76 \mathrm{pmol}$ of oleate slightly retarded the response decay. A 2-way ANOVA, including all 6 groups, across $t=135-240$ showed a significant effect of dose $(F=15.91, d f=5,144, p<0.001)$. Furthermore, when the ANOVA was restricted to the 4 groups that showed unimpaired initial potentiation (the 4 lowest doses), the effect of dose remained significant $(F=12.07, d f=3,96, p<0.001)$.

To compare the dose-response functions for molecular layer and hilar application, the responses at $t=240$ are plotted as a function of dose (Fig. 4). Since the $y$-axis is the population EPSP slope measure for the molecular layer records and the population spike amplitude measure for the hilar records, absolute heights of the 2 response functions should not be compared. However, it is clear that the dose-response functions for both loci have the shape of an inverted $U$, and that the optimal dose applied to the molecular layer is lower than the dose applied to the hilus.

\section{Measurement of $P K C$ activity: oleate/high-frequency synergism}

Since oleate, a PKC activator, prolongs LTP responses when applied together with 2 high-frequency trains, but has no effects on baseline synaptic transmission when applied alone, one would predict that PKC activation is not altered following oleate ejection alone, but would be when oleate was applied in conjunction with high-frequency stimulation. If PKC activation were the mechanism through which oleate enhancement of LTP were mediated, then it could be predicted that alterations of PKC would parallel the electrophysiological responses produced by oleate and high-frequency stimulation, alone and in combination.

\section{Protein kinase $C$ assays following oleate ejection alone}

Two groups received an ejection of $193 \mathrm{pmol}$ of oleate into the dentate molecular layer, following which perforant path-evoked responses were monitored at low frequency for 1 or $5 \mathrm{~min}$, at which point the animals were killed and the assay conducted. In addition, a control group received no ejection and was killed after receiving 120 min of test pulses. No significant differences in PKC activity could be seen across groups when measured in homogenate, or separated, cytosolic (C) and membrane (M) fractions (all $p>0.25$; see Table 1). Also, the index of PKC distribution, $M /(C+M)$, showed no significant alteration in localization of the PKC activity as a consequence of oleate ejection $(p>0.25)$. Thus, no alteration of PKC activity was observed as a consequence of oleate ejection.

\section{Protein kinase $C$ assays following oleate-enhanced LTP}

Three groups received either oleate (193 pmol), elaidate, or Tris ejections into the dentate molecular layer, followed by 2 highfrequency trains to induce LTP; animals were killed $60 \mathrm{~min}$ following the trains. Synaptic responses were monitored until the time of death. Tissue from these 3 groups was subjected to an assay of PKC activity. PKC activity was increased in the membrane and decreased in the cytosol of the oleate group (Table 1). It may also be seen that the PKC activity of the combined $(\mathrm{C}+\mathrm{M})$ fractions and the homogenate $(\mathrm{H})$ was not altered. Taken together, these data indicate that PKC activity was translocated to the membrane in the oleate group. This is supported by a significant increase in the $\mathrm{M} /(\mathrm{C}+\mathrm{M})$ measure of the oleate group compared to the Tris group $(F=7.53, d f=$ $1,6, p<0.05$; ANOVA). The percentage of PKC activity in the membrane $[M /(C+M)]$ is also significantly correlated with the percentage of baseline population EPSP slope measure just prior to death $(r=+0.760, d f=10, p<0.01)$.

\section{Mepacrine effects on LTP}

Inhibition of a persistent LTP response. If endogenous oleate release were critical for producing a persistent LTP response, then it could be predicted that blockade of the enzyme responsible for that release would inhibit the time course of the response. To test this prediction, each of 3 groups was implanted with recording/drug application electrodes in the dentate molecular layer. Two groups received ejections of either mepacrine, 

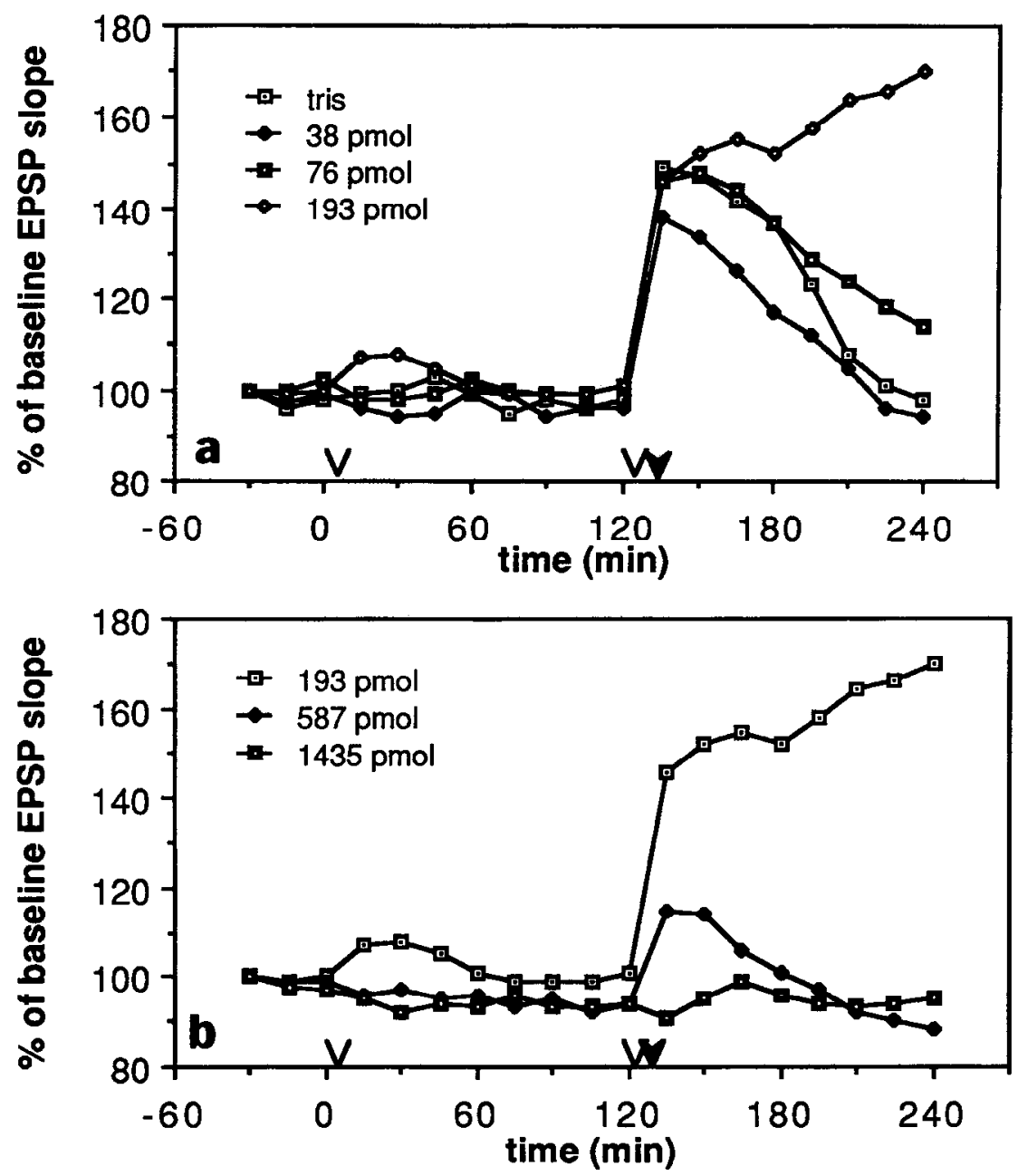

Figure 3. Oleate dose-response in the dentate molecular layer. The 2 highest doses, 587 and 1435 pmol (applied at $t=0$ and $t=120$, as indicated by the open arrowheads), were seen, respectively, to partially and completely inhibit the initial magnitude of the LTP response induced by 2 highfrequency trains ( filled arrowhead). Only the $193 \mathrm{pmol}$ dose was seen to induce persistence and growth of the potentiated response. The 76 pmol dose appeared to slightly retard the decay of the potentiated response. Two-way ANOVAs run among pairs of groups yielded significant differences between 193 and $76 \mathrm{pmol}(F=8.44, d f=1,48, p<0.01), 193$ and $587 \mathrm{pmol}(F=17.45, d f=1,48, p<0.001)$, and 76 and $587 \mathrm{pmol}(F=4.71$, $d f=1,48, p<0.05$ ). SEMs at $t=240$ were Tris, $4.8 ; 36$ pmol, $1.1 ; 76 \mathrm{pmol}, 4.2 ; 193 \mathrm{pmol}, 9.0 ; 587 \mathrm{pmol}, 6.8$; and $1435 \mathrm{pmol}, 4.3$.

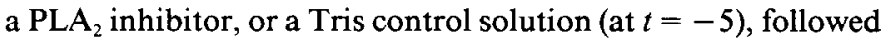
by 8 trains of high-frequency stimulation (Fig. 5). The third group received no ejection prior to the trains, but rather an ejection of mepacrine $5 \mathrm{~min}$ following the end of the trains. Eight trains of high-frequency stimulation typically produce a response that persists for at least $120 \mathrm{~min}$, thus allowing an inhibition of the potentiated response to be detectable.

No effect of drug treatment on the initial magnitude of potentiation was seen, as measured by population EPSP slope $(F=$ $0.86, d f=2,9, p>0.25$ ). Mepacrine applied immediately before, but not immediately after, the high-frequency stimulation was seen to drastically inhibit the persistence of the potentiated response, causing it to decay almost to baseline within $120 \mathrm{~min}$. This observation is supported by a 2-way ANOVA, including all 3 groups, across $\iota=0-120$ that yields a significant effect of treatment $(F=12.76, d f=2,81, p<0.001)$.

\section{Oleate reversal of mepacrine effects}

If the inhibition of the LTP time course produced by mepacrine is due to inhibition of $\mathrm{PLA}_{2}$-mediated oleate release, then one would expect that this inhibition could be reversed by oleate. Thus, each of 4 groups received an ejection of mepacrine into the molecular layer, followed immediately by 8 high-frequency trains. Four different procedures were undertaken to attempt to reverse the previously demonstrated mepacrine inhibition of the potentiated response. First, 193 pmol of oleate was ejected immediately prior to the mepacrine ejection. Second, using the same ejection parameters ( $25 \mathrm{nA}, 5 \mathrm{~min}$ ), elaidate, the transstereoisomer of oleate, was ejected immediately prior to the mepacrine ejection. Third, $193 \mathrm{pmol}$ of oleate was ejected 5 min after the end of the high-frequency trains $(10 \mathrm{~min}$ after mepacrine ejection). Fourth, 193 pmol of oleate was ejected 70 min after the end of the high-frequency trains $(75 \mathrm{~min}$ after mepacrine ejection).

Of these 4 treatments, only oleate application immediately before mepacrine ejection reversed the mepacrine inhibition of the potentiated response (Fig. 6). Within the 120 min monitoring period, this reversal of the mepacrine effect was total; a significant effect of treatment was seen across $t=0-120(F=$ 19.73, $d f=3,108, p<0.001$ ). Furthermore, 2-way ANOVAs 


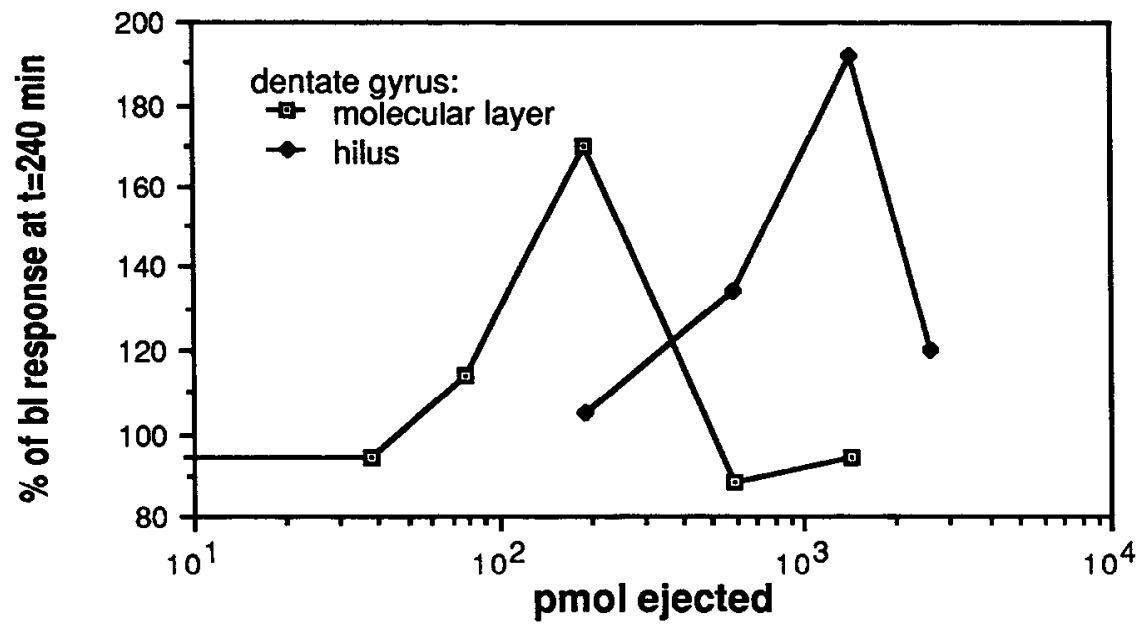

Figure 4. Oleate dose-response functions for molecular layer and hilar application. Data points from both application loci at $t=240(120$ min after 2 high-frequency trains were applied) are plotted as a function of dose. Thus, the relation between a given dose of oleate and the consequences of high-frequency stimulation may be observed. See text for interpretation.

run among pairs of the 3 groups that failed to show mepacrine reversal yielded no significant effect of treatment $(p>0.25$ for all).

\section{Discussion}

Calcium and PKC as synergistic signals

It has been proposed that intracellular $\mathrm{Ca}^{2+}$ and activation of PKC act synergistically to trigger prolonged hormone release in a number of non-neural systems (Kaibuchi et al., 1983; Michell, 1983; Kojima et al., 1984; see Nishizuka, 1986, for a review). Recently, we have proposed an analogous model, in which intracellular $\mathrm{Ca}^{2+}$ and PKC act synergistically to produce a persistent LTP response (Routtenberg, 1986). This model was based on the finding that neither the application of PKC-activating phorbol ester nor 2 trains of high-frequency stimulation alone could produce a persistent LTP response, but that when the 2 were applied together, a persistent LTP response was observed (Routtenberg et al., 1986). In addition, no difference in the initial magnitude of potentiation was seen between groups receiving phorbol ester plus 2-train stimulation and the carrier solution plus 2-train stimulation. The above findings, together with the lack of alteration in PKC or its substrates immediately following high-frequency stimulation (Akers et al., 1986; Lovinger et al., 1986), suggested that PKC modulates the duration of the LTP response, and that a $\mathrm{Ca}^{2+}$ influx produced by the 2 -train stimulation initiates the LTP response through non-PKC mechanisms.

An initial report using oleate in place of phorbol ester demonstrated the same synergism with the consequences of 2 highfrequency trains (Linden et al., 1986a). The results herein confirm and cxtend this synergism model.

Synergistic actions of cis-fatty acid and high-frequency stimulation; a proposed molecular mechanism

Oleate application in the absence of high-frequency stimulation did not affect synaptic transmission. This lack of effect was seen

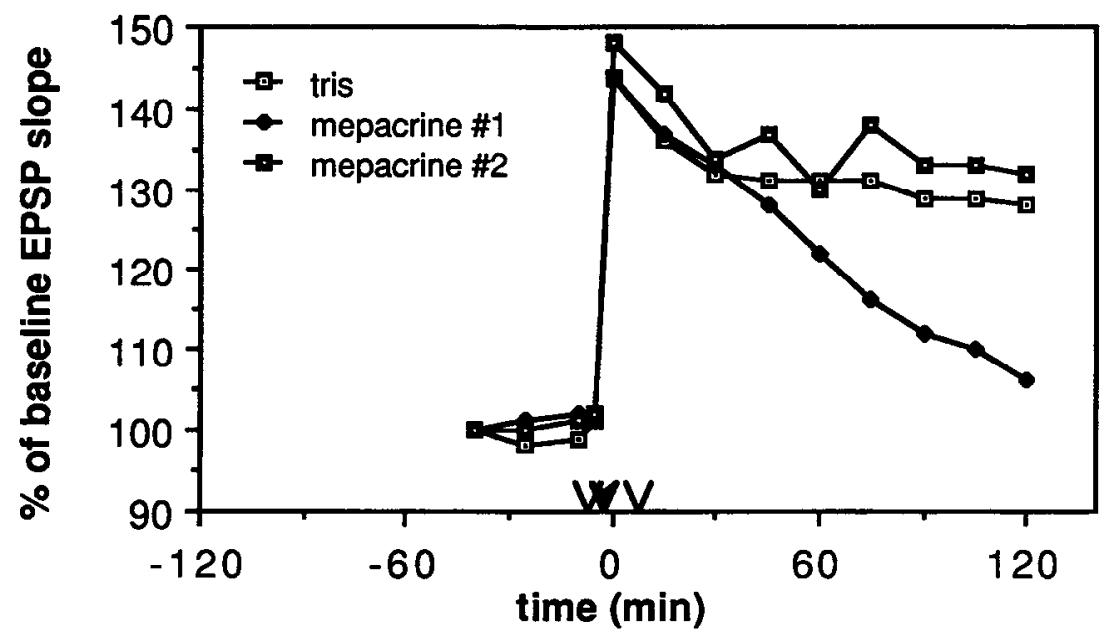

Figure 5. Mepacrine inhibits the time course of the LTP response. Ejection of mepacrine immediately prior (open arrowhead, $t=-5$; mepacrine $\# 1$ ) to 8 high-frequency trains (filled arrowhead) produced an inhibition of the potentiated response time course, causing it to decay almost to baseline within $120 \mathrm{~min}$. Application of a Tris control solution prior to the trains, or mepacrine ejection immediately after the trains (open arrowhead, $t=5$; mepacrine \#2) did not produce inhibition. Two-way ANOVAs yielded significant differences when run among the pairs, mepacrine \#1 and Tris $(F=17.64, d f=1,54, p<0.001)$, and mepacrine \#1 and mepacrine $\# 2(F=13.39, d f=1,54, p<0.001)$. No significant difference was seen between mepacrine \#2 and Tris $(F=1.58, d f=1,54, p>0.20)$. SEMs at $t=120$ were Tris, 4.3 ; mepacrine \#1, 4.5; and mepacrine \#2, 4.3. 


\begin{tabular}{|c|c|c|c|c|c|c|c|}
\hline \multirow[b]{2}{*}{ Group } & \multicolumn{5}{|c|}{ PKC activity ${ }^{a}$} & \multicolumn{2}{|c|}{ \% Baseline $\mathrm{EPSP}^{b}$} \\
\hline & $\begin{array}{l}\text { Cytosol } \\
\text { (C) }\end{array}$ & $\begin{array}{l}\text { Mem- } \\
\text { brane } \\
\text { (M) }\end{array}$ & $\mathrm{C}+\mathrm{M}$ & $\begin{array}{l}\mathrm{M} /(\mathrm{C}+\mathrm{M})^{c} \\
(\%)\end{array}$ & $\begin{array}{l}\text { Homoge- } \\
\text { nate }\end{array}$ & $t=0$ & $t=$ final \\
\hline \multicolumn{8}{|l|}{ Oleate alone } \\
\hline $\begin{array}{r}\text { Low-freq., } \\
120 \mathrm{~min}\end{array}$ & $\begin{array}{l}629 \\
(49)\end{array}$ & $\begin{array}{c}777 \\
(118)\end{array}$ & $\begin{array}{l}1046 \\
(135)\end{array}$ & $\begin{array}{l}54.4 \\
(3.3)\end{array}$ & $\begin{array}{r}1160 \\
(28)\end{array}$ & $\begin{array}{l}99.8 \\
(1.2)\end{array}$ & $\begin{array}{r}102.5 \\
(1.5)\end{array}$ \\
\hline $\begin{array}{l}\text { Oleate, } \\
11 \mathrm{~min}\end{array}$ & $\begin{array}{c}700 \\
(149)\end{array}$ & $\begin{array}{c}683 \\
(65)\end{array}$ & $\begin{array}{l}1383 \\
(139)\end{array}$ & $\begin{array}{l}49.6 \\
(2.2)\end{array}$ & $\begin{array}{l}1262 \\
(123)\end{array}$ & $\begin{array}{l}98.8 \\
(0.8)\end{array}$ & $\begin{array}{r}100.2 \\
(1.1)\end{array}$ \\
\hline $\begin{array}{l}\text { Oleate, } \\
5 \mathrm{~min}\end{array}$ & $\begin{array}{c}522 \\
(109)\end{array}$ & $\begin{array}{l}503 \\
(32)\end{array}$ & $\begin{array}{r}1025 \\
(64)\end{array}$ & $\begin{array}{l}49.4 \\
(3.3)\end{array}$ & $\begin{array}{r}1052 \\
(69)\end{array}$ & $\begin{array}{r}101.8 \\
(0.9)\end{array}$ & $\begin{array}{r}100.7 \\
(1.0)\end{array}$ \\
\hline \multicolumn{8}{|c|}{ Drug plus 2-train stimulation } \\
\hline $\begin{array}{l}\text { Tris, } \\
60 \mathrm{~min}\end{array}$ & $\begin{array}{l}1793 \\
(224)\end{array}$ & $\begin{array}{l}1220 \\
(268)\end{array}$ & $\begin{array}{l}3013 \\
(234)\end{array}$ & $\begin{array}{l}40.0 \\
(7.1)\end{array}$ & $\begin{array}{l}2156 \\
(268)\end{array}$ & $\begin{array}{r}142.5 \\
(1.7)\end{array}$ & $\begin{array}{r}129.2 \\
(2.4)\end{array}$ \\
\hline $\begin{array}{l}\text { Elaidate, } \\
60 \mathrm{~min}\end{array}$ & $\begin{array}{l}1394 \\
(227)\end{array}$ & $\begin{array}{l}1070 \\
(217)\end{array}$ & $\begin{array}{l}2465 \\
(213)\end{array}$ & $\begin{array}{l}43.5 \\
(7.2)\end{array}$ & $\begin{array}{l}1947 \\
(213)\end{array}$ & $\begin{array}{r}142.8 \\
(1.3)\end{array}$ & $\begin{array}{r}131.2 \\
(2.8)\end{array}$ \\
\hline $\begin{array}{l}\text { Oleate, } \\
60 \mathrm{~min}\end{array}$ & $\begin{array}{c}845 \\
(216)\end{array}$ & $\begin{array}{l}1664 \\
(180)\end{array}$ & $\begin{array}{l}2510 \\
(269)\end{array}$ & $\begin{array}{l}67.0 \\
(6.8)\end{array}$ & $\begin{array}{l}2420 \\
(211)\end{array}$ & $\begin{array}{r}142.2 \\
(1.8)\end{array}$ & $\begin{array}{r}149.2 \\
(1.7)\end{array}$ \\
\hline
\end{tabular}

${ }^{a}$ Protein kinease $\mathrm{C}$ activity is expressed in $\mathrm{pmol} / \mathrm{min}$ per $\mathrm{mg}$ protein.

${ }^{\circ}$ Electrophysiological measures in percentage of baseline population EPSP slope. SEM is given in parentheses.

cAn index of PKC distribution. Protein kinase $\mathrm{C}$ activity is not translocated to the membrane following oleate ejection alone, but is translocated $60 \mathrm{~min}$ after oleate-enhanced LTP.

across all the doses tested, both in hilus and molecular layer (Figs. 1-3). Two trains of high-frequency stimulation alone did not produce long-lasting effects, but when oleate and 2-train stimulation were given together, they acted synergistically to produce a persistent potentiated response.

What is the biochemical basis of this electrophysiological synergism? It has been reported that activation of $\mathrm{PKC}$ in vivo may be dependent upon translocation of the kinase from the cytosol to the phospholipid environment of the membrane (Kraft and Anderson, 1983). If oleate applied in the absence of high-frequency stimulation was incapable of translocating $\mathrm{PKC}$, then this might serve to explain why oleate does not affect low-frequency synaptic transmission.

Application of oleate (at a dose known to enhance the potentiated response produced by 2 trains of high-frequency stimulation) was not seen to alter PKC distribution or total PKC activity when measured 1 or $5 \mathrm{~min}$ after ejection. This is consistent with the above hypothesis. It is possible that oleate activates PKC with a delay of greater than $5 \mathrm{~min}$ after the end of the ejection. However, preliminary evidence from this laboratory has suggested that oleate alone did not induce PKC activation/redistribution 30 or $120 \mathrm{~min}$ after ejection (D. J. Linden,

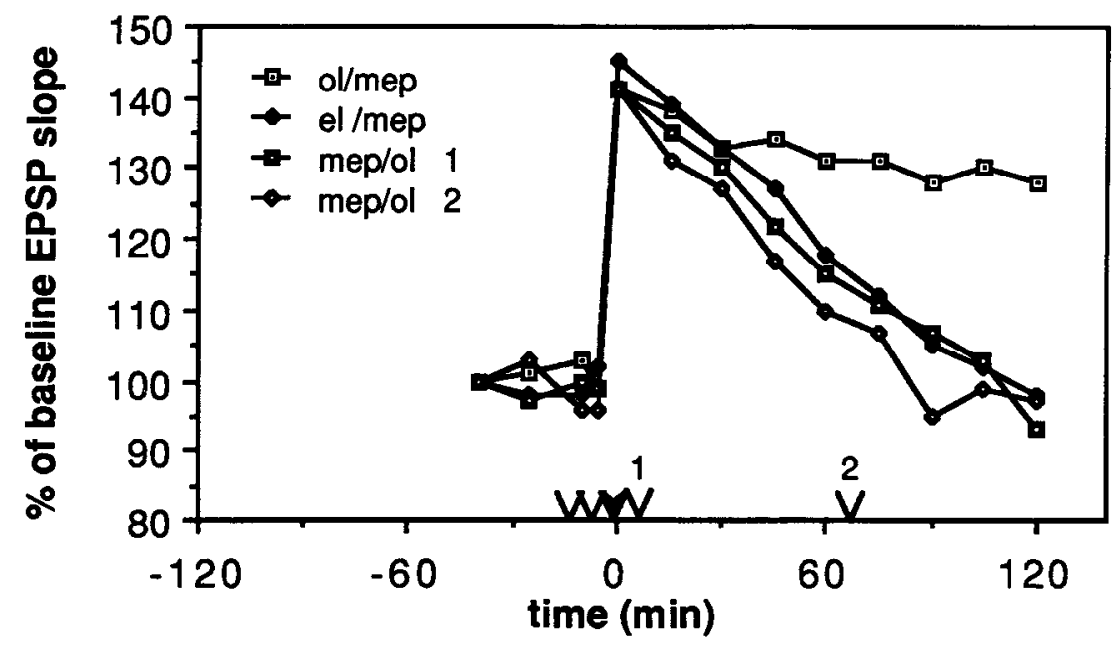

Figure 6. Mepacrine inhibition of the potentiated response is reversible by oleate. In all groups, mepacrine was applied (open arrowhead, $t=-5$ ) immediately prior to 8 high-frequency trains (filled arrowhead). Oleate application immediately prior to mepacrine ejection (open arrowhead, $t=$ $-10 ; \mathrm{ol} / \mathrm{mep}$ ) was seen to completely reverse the mepacrine inhibition of the potentiated response. Application of elaidate immediately prior to mepacrine ejection (el/mep), application of oleate $5 \mathrm{~min}$ after the end of the high-frequency trains (mep/ol 1 ), or application of oleate 70 min after the end of the high-frequency trains $(\mathrm{mep} / \mathrm{ol} 2)$ were all ineffective in reversing the mepacrine inhibition. Two-way ANOVAs yielded significant differences between the ol/mep and the el/mep $(F=23.12, d f=1,48, p<0.001)$, mep/ol \#1 $(F=17.15, d f=1,48, p<0.001)$, and mep/ol \#2 $(F=15.66, d f=1,48, p<0.001)$ groups. No significant difference was seen between the mep/ol \#1 and mep/ol \#2 groups $(F=0.73, d f=1,48, p>$ 0.25 ). SEMs at $t=120$ were ol/mep, 4.5 ; el/mep, 1.6 ; mep/ol \#1, 3.7; and mep/ol \#2, 1.2 . 
F. S. Sheu, and A. Routtenberg, unpublished observations).

When PKC distribution is assayed $60 \mathrm{~min}$ after oleate application together with 2 trains of high-frequency stimulation, PKC activity is translocated to the membrane relative to Tris and elaidate control groups. This suggests that oleate enhancement of 2-train LTP is mediated by persistent PKC activation. It is possible that the PKC translocation measured $60 \mathrm{~min}$ after oleate ejection plus 2-train stimulation is produced by ejected free oleate acting on PKC during the assay, rather than in vivo. However, this is unlikely, as exogenous free oleate has been reported to be maximally incorporated into phospholipid within 15 min (Yoshioka et al., 1986).

To explain the physiological and biochemical data obscrved, we propose that (1) oleate alone is incapable of translocating PKC; (2) 2 trains of high-frequency stimulation alter PKC, rendering it oleate-sensitive; (3) oleate applied in conjunction with 2 trains produces a strong activation/persistent translocation of PKC; (4) the strongly activated (translocated) PKC phosphorylates substrates (e.g., protein Fl) that mediate the persistent potentiated response. Thus, a strong or persistent activation of PKC is required to produce a persistent LTP response, and, consequently, neither 2-train stimulation nor oleate alone is sufficient. However, since PKC acts through phosphorylation of substrates, it is not necessary that $\mathrm{PKC}$ remain activated or translocated for the duration of the potentiated response.

We propose a hypothetical model in which 2-train stimulation renders $\mathrm{PKC}$ oleate-sensitive, but not strongly activated, thus priming PKC for activation by oleate. This is a refinement of our previously stated synergism model, which proposes that 2 trains act on non-PKC mechanisms to mediate the initiation of the LTP response. The present model proposes that 2-train stimulation initiates LTP through non-PKC mechanisms, and primes $\mathrm{PKC}$ by rendering it oleate-sensitive.

The action of 2-train stimulation on PKC that renders it oleate-sensitive may involve a weak/transient translocation of PKC to the membrane, which is then stabilized by the addition of oleate. Alternatively, 2-train stimulation may act on cytosolic PKC to render it oleate-sensitive in a manner that does not require any form of translocation. It should be noted that assays of PKC distribution following homogenization in the presence of chelators may strip loosely associated PKC from the membrane; consequently, the cytosol/membrane partition reported may actually be measuring a distinction between loosely and strongly membrane-associated PKC. However, if strongly associated PKC is the activated form, this does not require that the present model be altered.

Oleate has been reported to stimulate hydrolysis of phosphatidylinositides (Irvine et al., 1979), a process that results in release of diacylglycerol and inositol-1,4,5-triphosphate and consequent $\mathrm{PKC}$ activation. Could the oleate applied in these studies be acting on $\mathrm{PKC}$ by stimulating diacylgylcerol release rather than by direct activation? Half-maximal stimulation of phosphoinositide hydrolysis required $1.5 \mathrm{~mm}$ oleate, while the estimated dose of oleate applied in vivo (to enhance 2-train potentiation) was approximately 37 -fold lower. Thus, it appears unlikely that oleate stimulation of diacylglycerol release mediates the PKC activation observed in this report.

\section{Oleate may activate PKC in a different manner from that of phorbol esters}

The observation that PKC-activating oleate does not alter synaptic transmission when applied alone is in contrast to a report
(Malenka et al., 1986) using the PKC-activating phorbol ester (Castagna et al., 1982), phorbol dibutyrate (PDBu). Bath-application of a large dose of PDBu $(10 \mu \mathrm{M})$ to hippocampal slices was shown to increase synaptic transmission at the Schaffercollateral-CAl synapse. This distinction may represent a difference in the properties of oleate and $\mathrm{PDBu}$, or it may merely be indicative of differences in the regions studied (CA1 versus dentate gyrus), preparation used (slice versus intact), and method of drug application (bath versus local iontophoresis).

It is likely that there are significant distinctions in the mode of action of oleate (present study) and phorbol ester (Routtenberg et al., 1986). First, though both prolong LTP, phorbol esters have been reported to translocate PKC activity from the cytosol to the membrane in the process of activation (Kraft and Anderson, 1983), while oleate has not been seen to have this effect in the present study. In the context of the model presented above, it would be predicted that when PDBu translocates PKC activity, it would produce at least a transient enhancement of synaptic transmission.

Second, phorbol esters have been reported to be resistent to metabolic alteration, and consequently may be able to enhance synaptic transmission through continual activation of $\mathrm{PKC}$ over many minutes, while oleate is metabolized much more quickly; it may be seen that hilar ejection of oleate $120 \mathrm{~min}$ prior to delivery of 2 high-frequency trains failed to induce a persistent potentiated response, as is observed when oleate is applied immediately prior to the trains (Fig. 1). This implies that ejected oleate is metabolized, or incorporated into phospholipid, within $120 \mathrm{~min}$, rcndcring it unavailable to act synergistically with high-frequency stimulation.

\section{Locus of oleate action}

For both hilar and molecular layer application of oleate, there was a most effective dose for prolonging the potentiated response. The effective dose in the molecular layer (193 pmol) was about 7-fold lower than the effective dose in the hilus, suggesting that oleate is acting at the site of the terminals, rather than at the cell body layer (Fig. 4). This result is consistent with the hypothesis that oleate enhancement of LTP is mediated through PKC activation at the perforant path-granule cell synapses, since PKC has been reported to be enriched in synaptic membrane (Kikkawa et al., 1982). It has also been reported that PKC in the perforant path-granule cell synapse is localized to the presynaptic terminal (Worley et al., 1986), which implies that the action of PKC in LTP is on presynaptic functions (Routtenberg, 1985).

The highest doses of oleate applied in both the hilus and molecular layer inhibited the initial magnitude of potentiation (Figs. 2, 3), although these doses had no effect on baseline synaptic transmission when applied 120 min previously in the same animals. This result suggests that high concentrations of oleate can more easily disrupt processes that underlie a potentiated response than those that mediate baseline synaptic transmission. The mechanism by which these high doses of oleate inhibit potentiation is unknown. It is possible that this inhibition is a consequence of a generalized disruption or fluidization of the membrane, which has previously been reported following application of large doses of oleate (Hanski et al., 1979). In addition, recent work in our laboratory has shown that high concentrations of oleate can inhibit the phosphorylation of purified protein $\mathrm{F} 1$ by purified $\mathrm{PKC}$ in vitro, in the absence of membrane phospholipids (Chan et al., 1986a). 


\section{Role of phospholipase $A_{2}$ in LTP}

Previous data from this laboratory have shown PKC activators such as oleate (Linden et al., 1986a) and phorbol-12-myristate13-acetate (TPA) (Routtenberg et al., 1986) to prolong the duration, but not affect the initial magnitude, of LTP, suggesting that PKC activation does not mediate the initiation of LTP, but rather the persistence of potentiated response. This notion is strengthened by the present finding that application of the PLA inhibitor, mepacrine, immediately prior to 8 trains of highfrequency stimulation was seen to inhibit the persistence but not the initial magnitude of the potentiated response (Fig. 5). Thus, it is suggested that mepacrine inhibits the time course of the potentiated response by blocking $\mathrm{PLA}_{2}$-mediated oleate liberation and consequent PKC stimulation.

That mepacrine application immediately following high-frequency stimulation does not alter the potentiated response is indicative of 2 phenomena. First, this result suggests that the previously noted mepacrine inhibition of the persistent potentiated response if not merely a result of nonspecific "poisoning" of synaptic transmission. Second, it indicates that there is a time window for the mepacrine inhibition of the LTP response, which

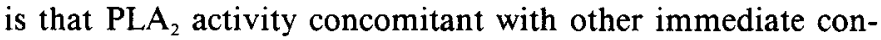
sequences of high-frequency stimulation is critical for mediating the persistence of LTP.

There are many PLA $\mathrm{A}_{2}$ inhibitors, but none of them, including mepacrine, $p$-bromophenacylbromide, tetracaine, chloroquine, and manoalide, are highly specific with regard to other phospholipases (Best et al., 1984; Glaser and Jacobs, 1986; R. S. Jacobs, personal communication). To address this issue, we were able to reverse the inhibitory effect of mepacrine selectively with oleate. Application of oleate immediately prior to mepacrine ejection, but not 5 or 70 min after high-frequency stimulation, was effective in completely reversing the mepacrine inhibition of the potentiated response (Fig. 6). This result is important in that it suggests that the mepacrine inhibition of the potentiated response is mediated through its inhibition of PLA $A_{2}$. In addition, it is significant that application of elaidate, the trans-stereoisomer of oleate, which is an ineffective PKC activator (Murakami and Routtenberg, 1985), failed to reverse the mepacrine effect. Thus, it appears that the oleate reversal of the mepacrine effect is dependent on its PKC-activating properties, rather than on either dilution of the mepacrine in vivo, or some nonspecific effect of fatty acids on the membrane. It should also be noted that mepacrine, in the concentration applied, has a minimal inhibitory effect on purified PKC, as measured in vitro $(10.4 \%$; K. Murakami, unpublished observations).

In addition to the present proposed $\mathrm{PLA}_{2}$-mediated release of cis-unsaturated fatty acids to stimulate PKC, PKC may also function in turn to modulate $\mathrm{PLA}_{2}$ activity. Lipocortin, an endogenous PLA $\mathrm{A}_{2}$ inhibitor (Hirata et al., 1982), is a PKC substrate and its activity may be modulated by phosphorylation (Hirata et al., 1984; Toqui et al., 1986).

In the absence of exogenous substances, 2-train stimulation produces a response that decays to baseline within $120 \mathrm{~min}$, while 8-train stimulation produces a response that persists and grows. What is the molecular distinction that underlies these different responses? We propose that endogenous oleate release by the $\mathrm{Ca}^{2+}$-dependent enzyme PLA $\mathrm{P}_{2}$ functions to mediate the persistent LTP response produced by 8 -train stimulation. Two trains of high-frequency stimulation produce changes in $\mathrm{PKC}$ that only render it oleate-sensitive, not strongly active, and thus produce an LTP response that decays to baseline values within $120 \mathrm{~min}$. However, 8 trains of high-frequency stimulation produce a sustained increase in intracellular $\mathrm{Ca}^{2+}$ (Krnjevic et al., 1986) that stimulates both (1) processes that render PKC olcatcsensitive and (2) $\mathrm{PLA}_{2}$-mediated liberation of free oleate and other $c i s$-fatty acids from the 2-acyl position of membrane phospholipids. In addition, while oleate activation of $\mathrm{PKC}$ is $\mathrm{Ca}^{2+}$ independent at high concentrations of oleate, low concentrations of oleate show $\mathrm{Ca}^{2+}$-dependent activation of $\mathrm{PKC}$ when either histone (Murakami et al., 1986) or purified protein F1 (Chan et al., 1986, and unpublished observations) is used as a substrate. Thus, free oleate could act on PKC to cause strong/persistent PKC activation, which is a prerequisite for a prolonged LTP response.

\section{References}

Akers, R. F., and A. Routtenberg (1985) Protein kinase C phosphorylates a $47 \mathrm{M}$ protein (F1) directly related to synaptic plasticity. Brain Res. 334: 147-151.

Akers, R. F., D. M. Lovinger, P. A. Colley, D. J. Linden, and A. Routtenberg (1986) Translocation of protein kinase C activity may mediate hippocampal long-term potentiation. Science 231: 587-589.

Andersen, P., B. Holmqvist, and P. E. Voorhoeve (1966) Entorhinal activation of dentate granule cells. Acta Physiol. Scand. 66: 448-460.

Best, L., A. Sener, P. C. F. Mathias, and W. J. Malaisse (1984) Inhibition by mepacrine and $p$-bromophenacylbromide of phosphoinositide hydrolysis, glucose oxidation, calcium uptake and insulin release in rat pancreatic islets. Biochem. Pharmacol. 33: 2657-2662.

Bliss, T. V. P., and T. I omo (1973) Long-lasting potentiation of synaptic transmission in the dentate area of the anesthetized rabbit following stimulation of the perforant path. J. Physiol. (Lond.) 232: 334356.

Castagna, M., Y. Takai, K. Kaibuchi, K. Sano, U. Kikkawa, and Y. Nishizuka (1982) Direct activation of calcium-activated, phospholipid dependent protein kinase by tumor-promoting phorbol esters. J. Biol. Chem. 257: 7551-7847.

Chan, S. Y., K. Murakami, and A. Routtenberg (1986a) Characterization of purified protein $\mathrm{Fl}$, a specitic protein kinase $\mathrm{C}$ substrate. Soc. Neurosci. Abstr. 12: 1169.

Chan, S. Y., K. Murakami, and A. Routtenberg (1986b) Phosphoprotein F1: Purification of a brain kinase $\mathrm{C}$ substrate related to plasticity. $\mathrm{J}$. Neurosci. 6: 3618-3627.

Gispen, W. H., and A. Routtenberg (eds.) (1986) Phosphoproteins in Neuronal Function, Elsevier, Amsterdam.

Glaser, K. B., and R. S. Jacobs (1986) Molecular pharmacology of manoalide: Inactivation of bee venom phospholipase A2. Biochem. Pharmacol. 35: 449-453.

Hanski, E., G. Rimon, and A. Levitzki (1979) Adenylate cyclase activation by the beta-adrenergic receptor as a diffusion-controlled process. Biochemistry 18: 846-853.

Hirata, F., Y. Notsu, M. Iwata, L. Parente, M. DiRosa, and R. J. Flower (1982) Identification of several species of phospholipase inhibitory protein(s) by radioimmunoassay for lipomodulin. Biochem. Biophys. Res. Commun. 109: 223-230.

Hirata, F., K. Matsuda, Y. Notsu, T. Hattori, and R. Del Carmine (1984) Phosphorylation at a tyrosine residue of lipomodulin in mitogen-stimulated murine thymocytes. Proc. Natl. Acad. Sci. USA 81: $4717-4721$.

Irvine, R. F., A. J. Letcher, and R. M. C. Dawson (1979) Fatty acid stimulation of membrane phosphatidylinositol hydrolysis by brain phosphatidylinositol phosphodiesterase. Biochem. J. 178: 497-500.

Kaibuchi, K., Y. Takai, M. Sawamura, M. Hoshijima, T. Fujikura, and Y. Nishizuka (1983) Synergistic functions of protein phosphorylation and platelet activation. J. Biol. Chem. 258: 6701-6704.

Kikkawa, U., Y. Takai, R. Minakuchi, S. Inohara, and Y. Nishizuka (1982) Calcium-activated phospholipid-dependent protein kinase from rat brain: Subcellular distribution, purification and properties. J. Biol. Chem. 257: 13341-13348.

Kojima, I., K. Kojima, D. Kreutter, and H. Rasmussen (1984) The temporal integration of the aldosterone secretory response of angiotensin occurs via two intracellular pathways. J. Biol. Chem. 259: 14448-14457. 
Kraft, A. S., and W. B. Anderson (1983) Phorbol esters increase the amount of $\mathrm{Ca}^{2+} /$ phospholipid dependent protein kinase associated with plasma membrane. Nature 301: 621-623.

Krnjevic, K., M. E. Morris, and N. Ropert (1986) Changes in free calcium ion concentration recorded inside hippocampal pyramidal cells in situ. Brain Res. 374: 1-11.

Linden, D. I., K. Murakami, and A. Routtenberg (1986a) A newly discovered protein kinase $C$ activator (oleic acid) enhances long-term potentiation in the intact hippocampus. Brain Res. 379: 358-363.

Linden, D. J., K. Murakami, and A. Routtenberg (1986b) Oleic acid, a protein kinase $\mathrm{C}$ activator, enhances hippocampal long-term potentiation. Soc. Neurosci. Abstr. 12: 1169.

Lomo, T. (1971) Patterns of activation in a monosynaptic cortical pathway: The perforant path input to the dentate area of the hippocampal formation. Exp. Brain Res. 12: 18-45.

Lovinger, D. M., P. A. Colley, R. F. Akers, R. B. Nelson, and A. Routtenberg (1986) Direct relation of long-term synaptic potentiation to phosphorylation of membrane protein $\mathrm{Fl}$, a substrate for membrane protein kinase C. Brain Res. 399: 205-211.

Lowry, O., N. J. Rosebrough, and R. J. Randall (1951) Protein measurement with the Folin phenol reagent. J. Biol. Chem. 193: 265275.

Malenka, R. C., D. V. Madison, and R. A. Nicoll (1986) Potentiation of synaptic transmission in the hippocampus by phorbol esters. $\mathrm{Na}$ ture 321: $175-177$.

Mallorga, P., J. F. Tallman, R. C. Henneberry, F. Hirata, W. T. Strittmatter, and J. Axelrod (1980) Mepacrine blocks beta-adrenergic agonist-induced desensitization in astrocytoma cells. Proc. Natl. Acad. Sci. USA 77: 1341-1345.

McCrimmon, D. R., J. L. Feldman, and D. F. Speck (1986) Respiratory motoneuronal activity is altered by injections of picomoles of glutamate into cat brain stem. J. Neurosci. 6: 2384-2392.

McNaughton, B. L. (1982) Long-term synaptic enhancement and shortterm potentiation in rat fascia dentata act through different mechanisms. J. Physiol. (Lond.) 324: 249-262.

Michell, B. (1983) $\mathrm{Ca}^{2+}$ and protein kinase C: Two synergistic cellular signals. Trends Biochem. 8: 263-265.

Murakami, K., and A. Routtenberg (1985) Direct activation of purified protein kinase $\mathrm{C}$ by unsaturated fatty acids (oleate and arachidonate) in the absence of phospholipids and $\mathrm{Ca}^{2+}$. FEBS Lett. 192: 189-193.
Murakami, K., S. Y. Chan, and A. Routtenberg (1986) Protein kinase Cactivation by $c i s$-fatty acid in the absence of $\mathrm{Ca}^{2+}$ and phospholipid. J. Biol. Chem. 261: 15424-15429.

Nelson, R. B., and A. Routtenberg (1985) Characterization of protein F1 (47 kDa, $4.5 \mathrm{pI})$ : A kinase C substrate directly related to neural plasticity. Exp. Neurol. 89: 213-224.

Nishizuka, Y. (1986) Studies and perspectives of protein kinase C. Science 233: 305-312.

Routtenberg, A. (1985) Protein kinase C activation leading to protein F1 phosphorylation may regulate synaptic plasticity by presynaptic terminal growth. Behav. Neural Biol. 44: 186-200.

Routtenberg, A. (1986) Synaptic plasticity and protein kinase C. In Phosphoproteins in Neuronal Function, W. H. Gispen and A. Routtenberg, eds., pp. 211-234, Elsevier, Amsterdam.

Routtenberg, A., D. M. Lovinger, and O. Steward (1985) Selective increase in the phosphorylation of a $47 \mathrm{kD}$ protein ( $\mathrm{Fl}$ ) directly related to long-term potentiation. Behav. Neural Biol. 43: 3-11.

Routtenberg, A., P. Colley, D. Linden, D. Lovinger, K. Murakami, and F.-S. Sheu (1986) Phorbol ester promotes growth of synaptic plasticity. Brain Res. 378: 374-378.

Takai, Y., A. Kishimoto, M. Inoue, and Y. Nishizuka (1977) Studies on a cyclic nucleotide independent protein kinase and its proenzyme in mammalian tissues. J. Biol. Chem. 252: 7603-7609.

Takai, Y., A. Kishimoto, Y. Iwasa, Y. Kawahara, T. Mori, and Y. Nishizuka (1979) Calcium-dependent activation of a multifunctional protein kinase by membrane phospholipids. J. Biol. Chem. 254: 3692-3695.

Toqui, L., B. Rothhut, A. M. Shaw, A. Fradin, B. B. Vargaftig, and F. Russo-Marie (1986) Platelet activation-a role for a $40 \mathrm{~K}$ antiphospholipase A2 protein indistinguishable from lipocortin. Nature 321: 177-180.

Worley, P. F., J. M. Baraban, E. B. De Souza, and S. H. Snyder (1986) Mapping second messenger systems in the brain: Differential localizations of adenylate cyclase and protein kinase C. Proc. Natl. Acad. Sci. USA 83: 4053-4057.

Yoshioka, S., S. Nakashima, Y. Okano, and Y. Nozawa (1986) Arachidonic acid mobilization among phospholipids in murine mastocytoma P-815 cells: Role of ether-linked phospholipids. J. Lipid Res. 27: 939-944. 